\title{
The improvement of the environment in the sea by the creation of tidal flats and shallow waters utilizing dredged sand
}

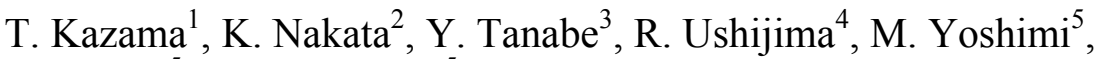 \\ I. Oshima ${ }^{5} \&$ T. Nagakura ${ }^{5}$ \\ ${ }^{1}$ Metocean Environment Inc., Japan \\ ${ }^{2}$ School of Marine Science and Technology, Tokai University, Japan \\ ${ }^{3}$ Ministry of Land, Infrastructure and Transport (MLIT), \\ Chubu Regional Bureau, Mikawa Port Office, Japan \\ ${ }^{4}$ Ministry of Land, Ports and Harbours Bureau, \\ Environment Planning Office, Japan \\ ${ }^{5}$ Water Vitalization and Environment Research Center, Japan
}

\begin{abstract}
Extensive tidal flats and shallow waters used to exist in Mikawa Bay. About $17 \%$ of them have been lost by land reclamation, etc. It is known that deterioration of water purification ability due to the loss of many tidal flats and shallow waters has caused various environmental problems such as red tide, oxygen-depleted water and so on. In order to make navigation safer, the Ministry of Land, Infrastructure and Transport (MLIT) dredged Nakayama Waterway at the mouth of Mikawa Bay between 1998 and 2004. The MLIT and Aichi Prefecture are jointly created tidal flats and shallow waters by the dredged materials in environmental rehabilitation inside Mikawa Bay. In the districts of created tidal flats and shallow waters, monitoring surveys have been conducted on environmental conditions such as water quality, sediment quality, and benthos. Here, we report on the monitoring results of tidal flat creation utilizing dredged sand in the Mito and Nishiura districts at the innermost part of Mikawa Bay. From the second year after the creation of the tidal flat, bivalves such as Ruditapes philippinarum and Mactra chinensis increased. The recovery of benthos, in particular, is likely to be due to the reduction of oxygen-depleted water as a result of the creation of the shallow site. Improvement of water purification ability is expected due to the increase of bivalve shellfish, which has high water purification ability.

Keywords: creation of tidal flat, dredged sand, water purification ability.
\end{abstract}




\section{Introduction}

Mikawa bay is calm and having rich biological resources waters of about $600 \mathrm{~km}^{2}$ in the area semi-enclosed by the Chita and Atsumi peninsulas in Japan (Fig. 1), and it has been familiar to us as a place for marine transportation, fishing, and recreation. However, the water exchange ability is low because the bay entrance part is narrow, and pollutant loading from land is likely to accumulate. Before 1960, extensive tidal flats and shallow waters existed in Mikawa Bay. About $17 \%$ of them have been lost by land reclamation etc (Fig. 2). Red tide and low oxygen water are likely to form, and has an effect on fishing, etc. To improve the water quality environment of Mikawa bay, the Ministry of Land Infrastructure and Transport (MLIT) and Aichi Prefecture used dredging sand from the Nakayama waterway in the bay entrance part and created tidal flats and shallows. In the districts of created tidal flats and shallow waters, monitoring surveys have been conducted on environmental conditions such as water quality, sediment quality, and benthos. Here, we report on the monitoring results of the created tidal flat.

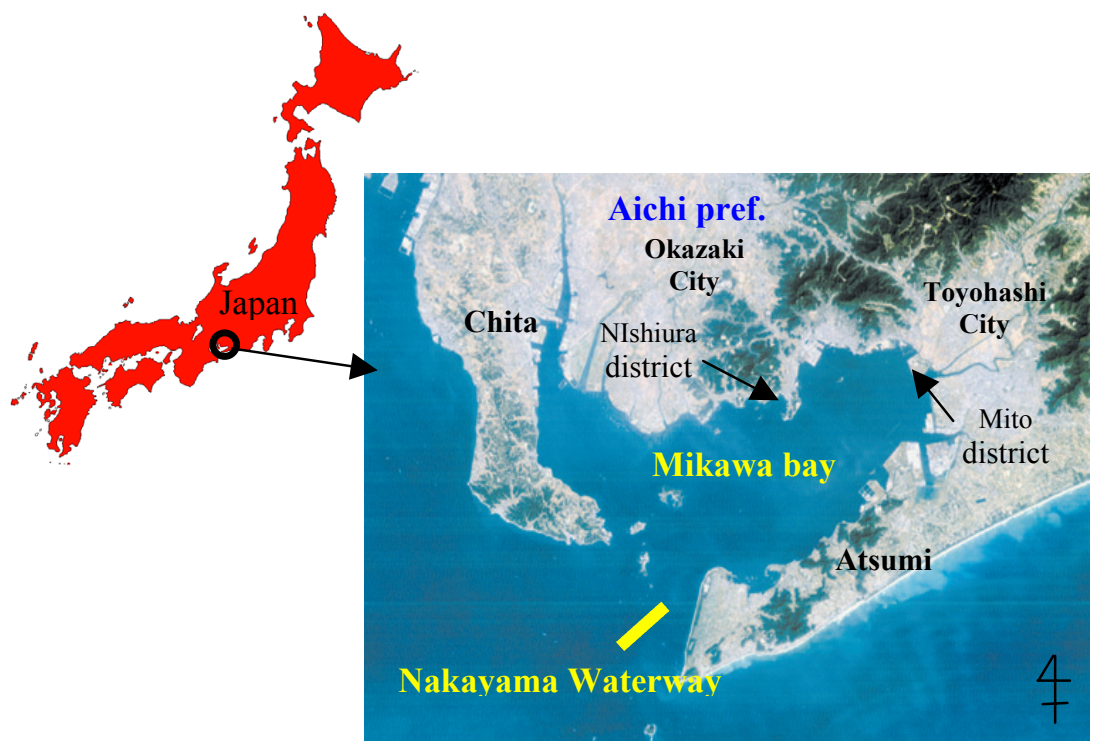

Figure 1: The location of Mikawa bay. 


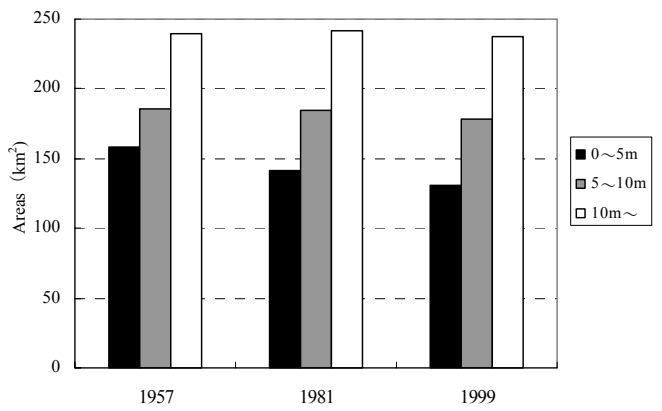

Figure 2: $\quad$ Transition of area of shallows in Mikawa bay.

\section{Sampling sites and method}

Here, it introduces the monitoring survey on the Mito site and the Nishiura site among the created tidal flats. The monitoring survey on the Mito site continued for 6 years from 1998 to 2004, and for 6 years from 1999 to 2005 on the Nishiura site. In both of the created tidal flats, the monitoring surveys have been conducted on environmental conditions such as water quality, sediment quality, and benthos. The sampling method is as shown in the following. The outline of the sampling method is shown in Fig. 3.

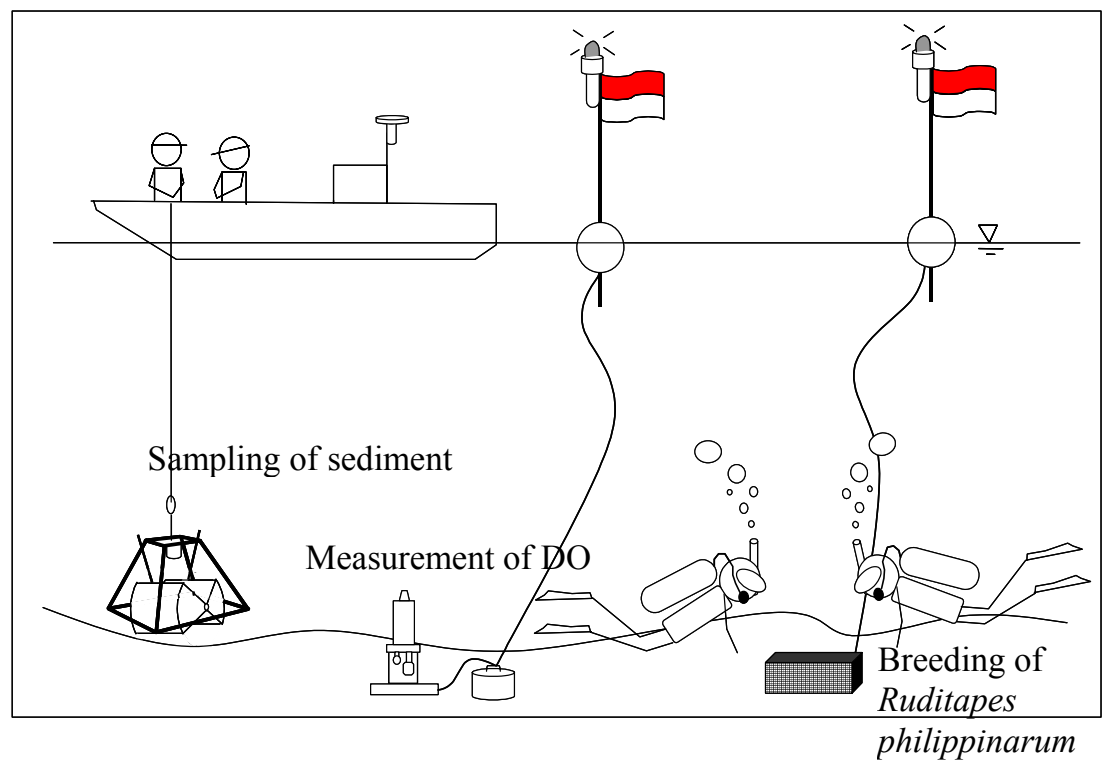

Figure 3: The outline of the sampling method. 


\subsection{Benthos}

The bottom sediment on the created tidal flat and the adjacent sea area was gathered three times using a Smith McIntyre type sampler. The sample was sieved with a $1 \mathrm{~mm}$ mesh sieve, and measured the number and weight of samples of each benthic fauna species. The sampling was conducted every season.

\subsection{Sediment quality}

The bottom sediment analysis items were a grain degree composition, an ignition loss, and a sulphide, etc. The sampling was conducted every season.

\subsection{The relation between dissolved oxygen and the survival rate of Ruditapes philippinarum}

Dissolved oxygen concentration in the bottom layer at the Mito site during the summer (from June to August 1999) was continuously measured by setting up the DO meters. At the same time, bivalve, Ruditapes philippinarum, was put in a hutch and sank to the sea bottom, and then the life and death of Ruditapes philippinarum in that was observed regularly.

\section{Monitoring survey}

\subsection{Benthos}

The diversity of benthic species at the created tidal flat is shown in Fig. 4. The diversity of benthic species increased gradually with time, and we confirmed about 20 species in both sites in about 60 months. There was a time when more than the tidal flat benthos appeared in the adjacent sea area, and was a time that almost became an inanimate. There were about 20 species of benthos in a peripheral natural tidal flat (the tidal flat of Toyokawa river mouth), and it was the same level as the created tidal flat.

Next, the change in the number of bivalves (Mactra chinensis, Phacosoma japonicum, Ruditapes philippinarum) in the Mito site is shown in Fig. 5. The number of bivalves increased until about 2 or 3 years after having been created. However, the number of bivalves decreased a little after that. 


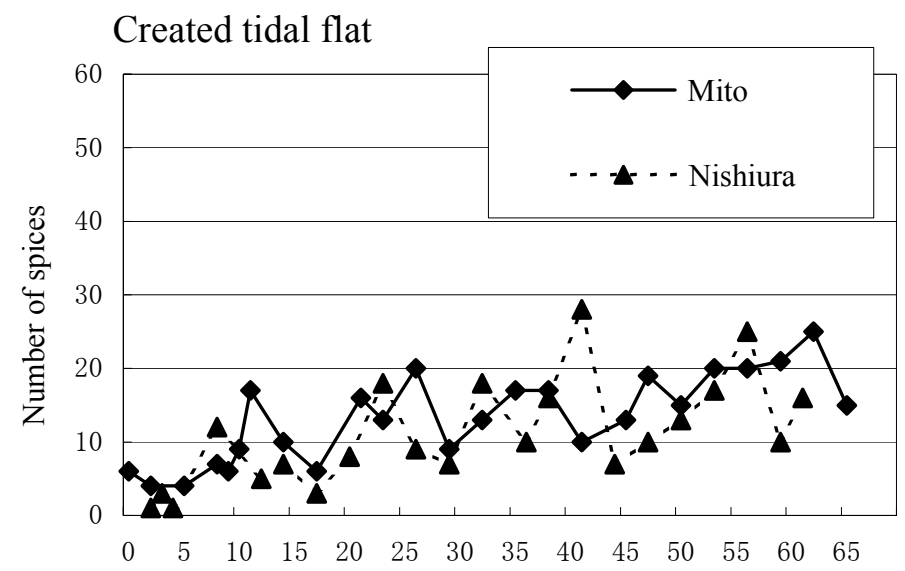

Adjacent sea area
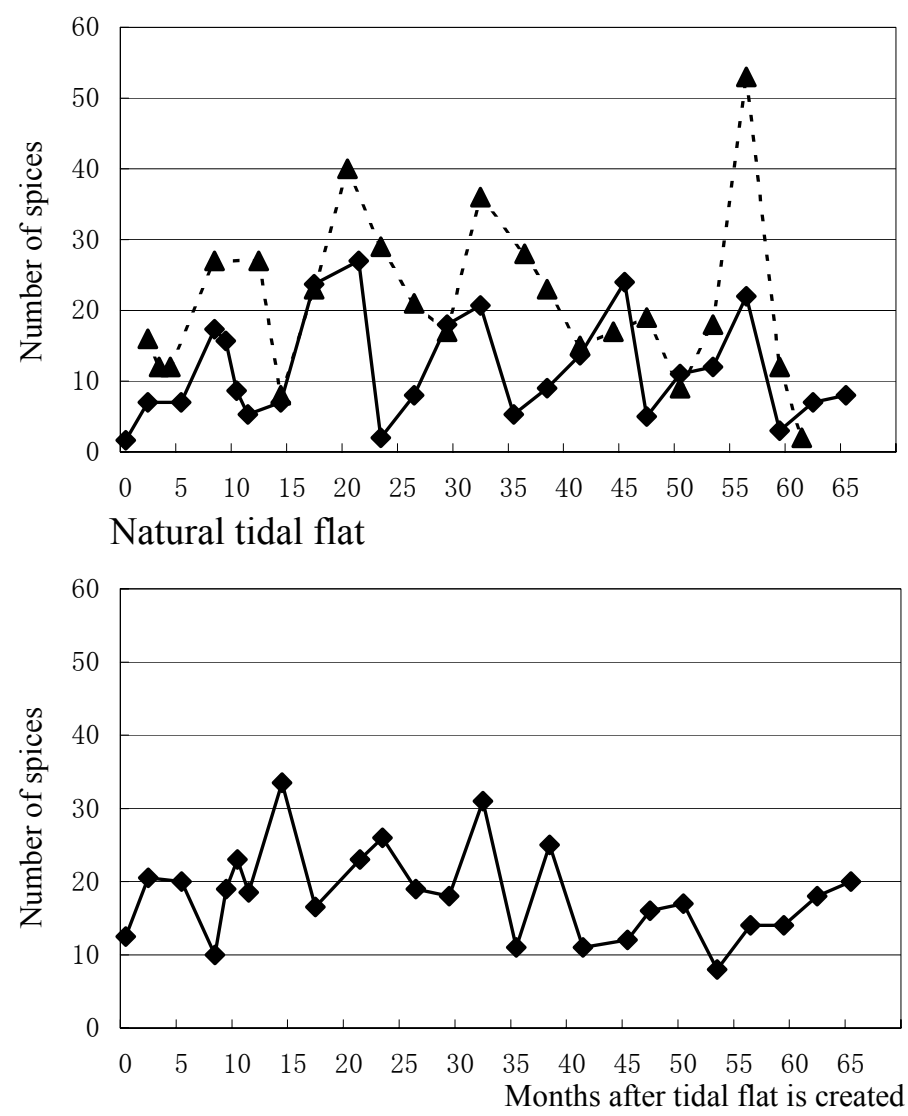

Figure 4: The diversity of benthic species at the created tidal flat. 


\section{Mactra chinensis}

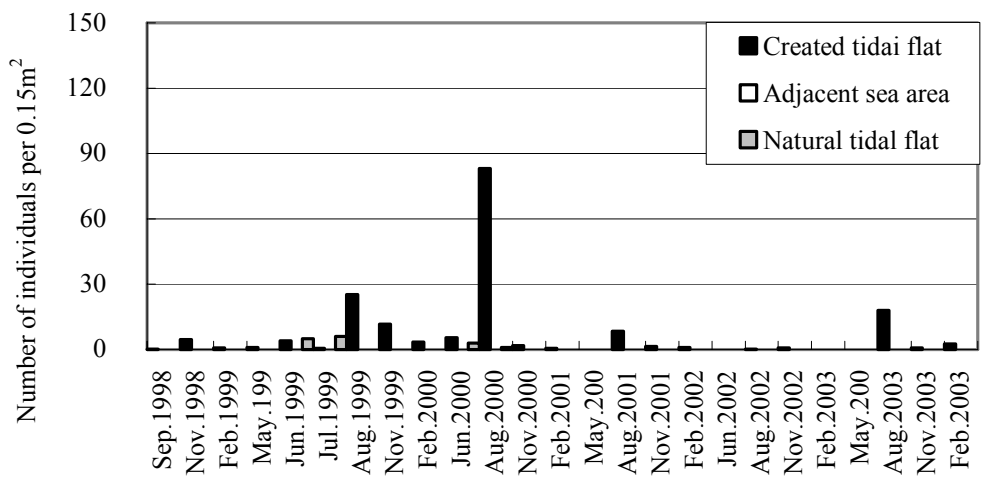

\section{Phacosoma japonicum}
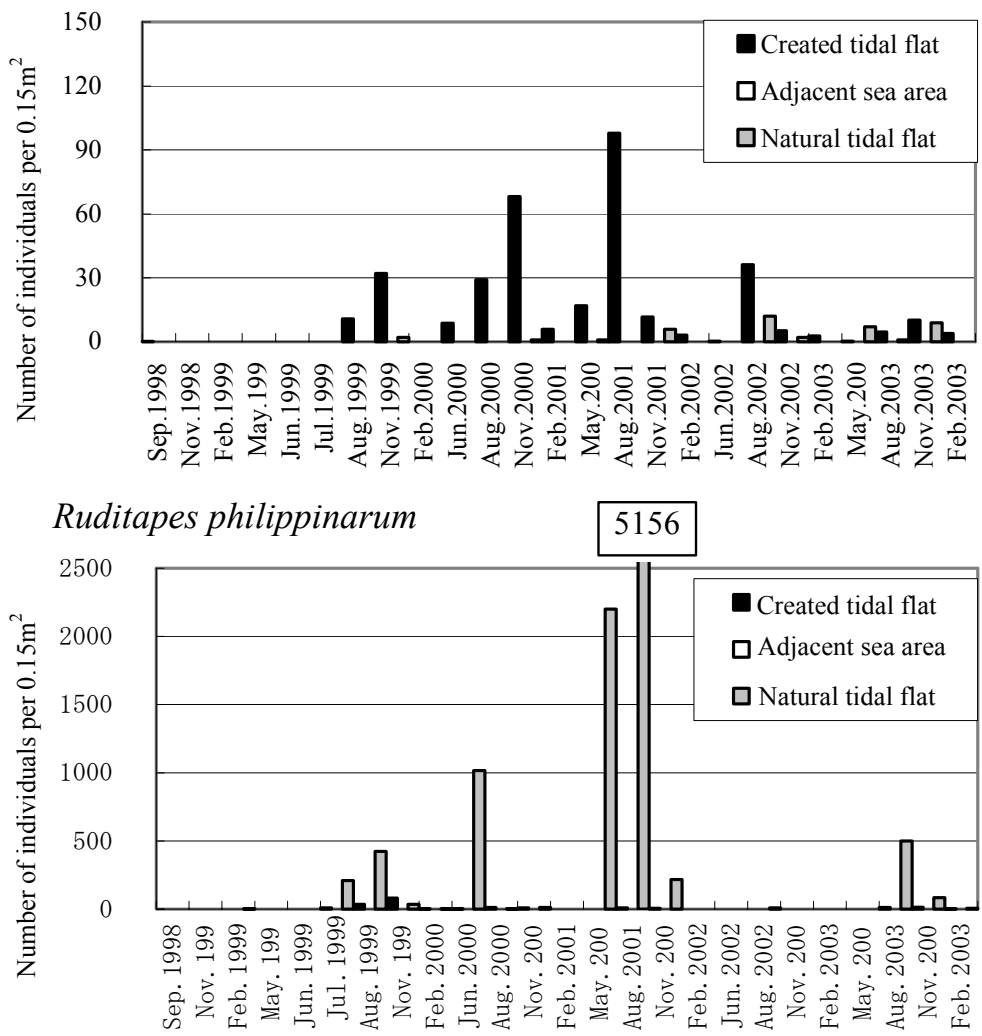

Figure 5: The change in the number of bivalves (Mactra chinensis, Phacosoma japonicum, Ruditapes philippinarum) in the Mito site. 


\subsection{Sediment quality}

The change of grain size composition in the Nishiura district is shown in Fig. 6.The tidal flat creation material was a uniform particle size for which fine sand accounted for $90 \%$ or more, and it hardly changed for 5 years after it had been created. On the other hand, the grain size composition of the adjacent sea area in Nishiura district had mixed with fine sand, the silt/clay, and gravel.
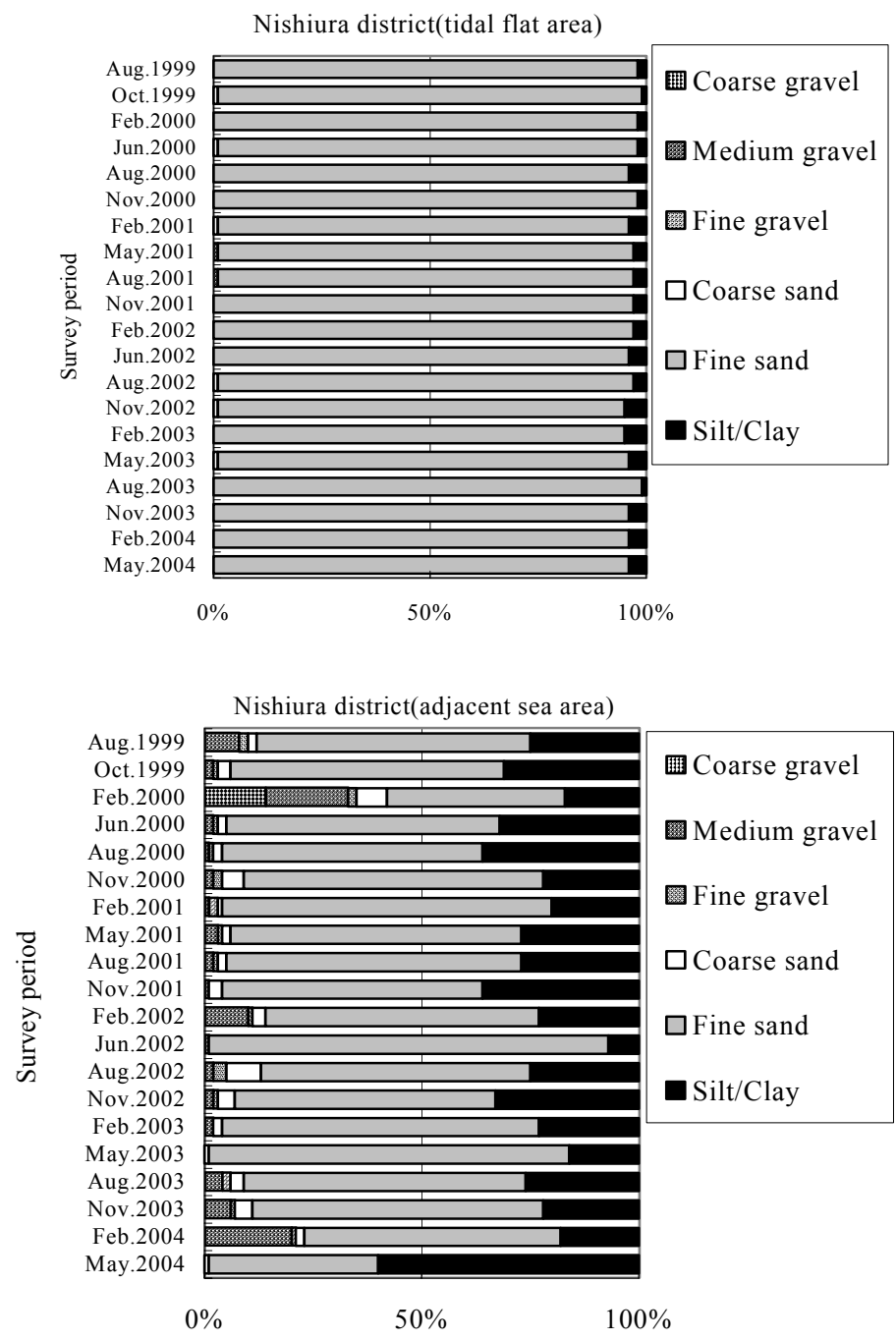

Figure 6: The change of grain degree composition in the Nishiura district. 


\subsection{The relation between dissolved oxygen and the survival rate of Ruditapes philippinarum}

The observed results of DO concentration and the survival rate of Ruditapes philippinarum on the created tidal flat area (water depth $3 \mathrm{~m}$ ) and on the adjacent area (water depth $5 \mathrm{~m}$ ) are shown in Fig.7. The survey period was between June and August 1999. The left y-axis shows the DO concentration and the right yaxis the survival rate. In the adjacent sea area, oxygen depletion persisted for several days, but in the created tidal flat area, oxygen depletion persisted for only short periods. With regard to the survival rate of Ruditapes philippinarum, the survival rate in the created tidal flat was around $80 \%$, whereas in the adjacent area almost all clams died. New clams were re-introduced into the adjacent area but most examples died again.

On the created tidal flat where the depth is $3 \mathrm{~m}$

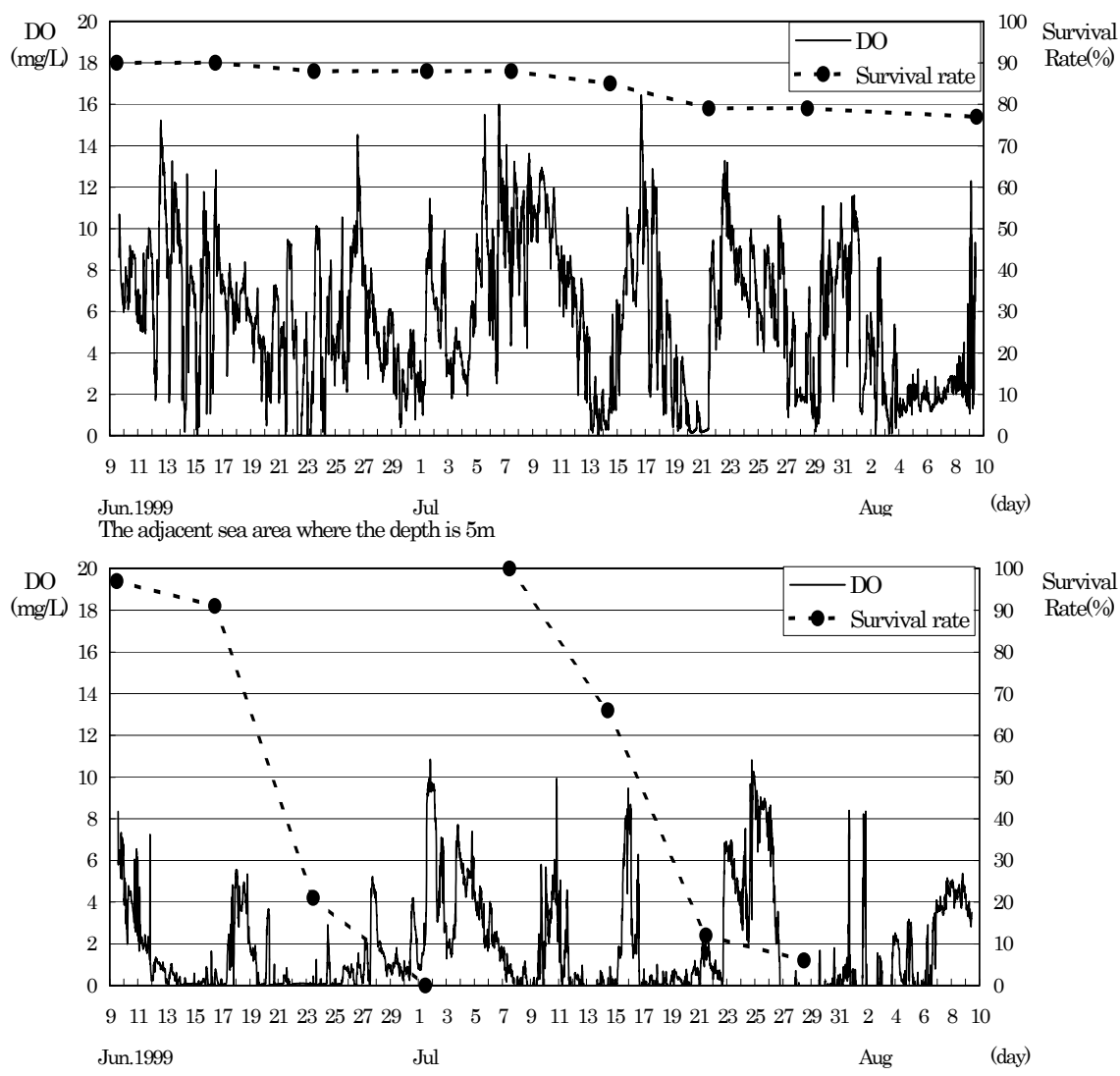

Figure 7: The DO concentration and survival rate of Ruditapes philippinarum. 


\subsection{Estimation of water quality purification ability by benthos}

The removal rate of organic nitrogen from the water column by the benthos was estimated using the survey results of benthos and sediment quality. A simple method by Suzuki et al. [1] was employed to estimate the rate. The mean, the maximum and the minimum values in the created tidal flats, the adjacent sea area and the natural tidal flat are shown in Fig. 8. The mean value at the removal rate of organic nitrogen on the created tidal flat was $131.7 \mathrm{mgN} / \mathrm{m}^{2} /$ day. The value was about five times greater than in the adjacent sea area. The removal rate of organic nitrogen tended to be high with depth. It depends on the biomass of bivalves such as Ruditapes philippinarum that take the organism in water.
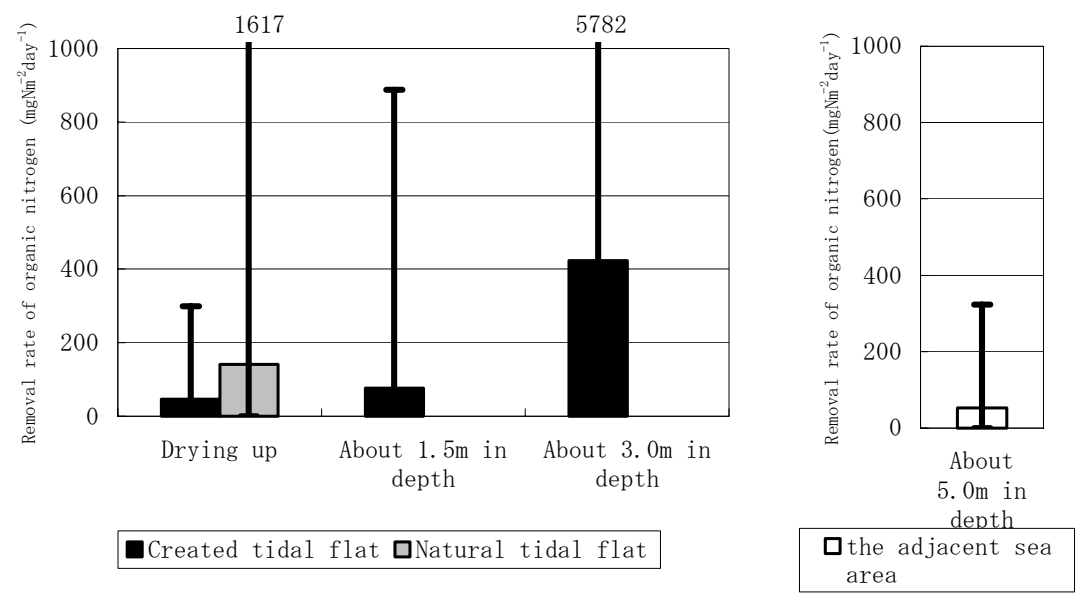

Figure 8: Estimation results of water purification capacity.

\section{Conclusion}

The conclusions from this study are as follows:

- Areas of oxygen depleted waters decreased through creation of tidal flat due to the elevation of the seafloor.

- Colonization by benthic species such as bivalves has been identified in the created tidal flat. Their abundance was constantly larger than the adjacent area.

- $\quad$ The created tidal flat showed higher water purification capacity compared to the adjacent area, mainly due to the higher abundance of benthic species. 


\section{Future topics}

The future topics are as follows:

- To further enhance the water purification capacity, intentional removal of benthic species from the Bay system is necessary, through promoting activities such as clam digging.

- Created tidal flat tend to have hard substrate, which hinders burrowing of benthic species. Use of muddy dredged sediments is considered as an option to soften the substrate.

\section{Reference}

[1] Teruaki Suzuki, Hiroaki Aoyama, Toru Nakao and Kazumasa Imao Tentative Minimum Standards for Bottom Sediment Quality Based on the Water Purification Function of the Macrobenthic Community -A Model Study Conducted in the Shallow Areas of Mikawa Bay-. Bulletin of the Japanese Society of Fisheries Oceanography, 64(2), pp.85-93, 2000. 